REVES - Revista Relações Sociais, Vol. 05 N. 01 (2022)

https://periodicos.ufv.br/reves

eISSN: $2595-4490$

REVES - Revista Relaçöes Sociais (eISSN 2595-4490)

\title{
O Estado da Arte em políticas públicas educacionais de gênero no Brasil
}

The state of the art in gender educational public policies in Brazil

Silvana Barreto Oriente

ORCID: https://orcid.org/0000-0001-7957-0070

Universidade Federal do Amazonas, Brasil

E-mail: silvanaboriente@gmail.com

Maria Isabel Alonso Alves

ORCID: https://orcid.org/0000-0002-2960-1200

Universidade Federal do Amazonas, Brasil

E-mail: profamariaisabel@ufam.edu.br

Article Info:

Article history: Received 2021-12-19

Accepted 2022-01-19

Available online 2022-01-20

doi: $10.18540 /$ revesvl5iss1pp13777-01-16e

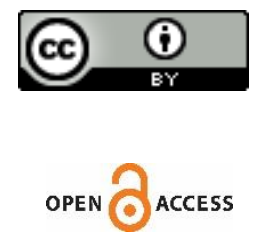

Resumo: Esse artigo aborda o Estado da Arte das políticas públicas educacionais que amparam as questões de gênero no Brasil. Trata-se de um recorte de pesquisa em andamento desenvolvida no Programa de Pós-Graduação em Ensino de Ciências e Humanidades (PPGECH) no âmbito da Universidade Federal do Amazonas - UFAM, Unidade de Humaitá - IEAA. Neste recorte busca-se fazer uma revisão de literatura sobre as pesquisas em torno das políticas educacionais voltadas as questões de gênero no Brasil, nos últimos cinco anos. Trata-se de uma pesquisa bibliográfica, realizada a partir da base de dados de periódicos da Coordenação de Aperfeiçoamento de Pessoal de Nível Superior - CAPES, com recorte temporal de cinco anos (2016 a 2021), de abordagem qualitativa, a partir dos descritores: políticas educacionais e gênero; gênero e educação. A análise e discussão dos dados foram realizadas inspirados nos estudos pós-críticos em educação, com base em autores que transitam entre os campos de prefixos "pós", a partir de Meyer e Paraíso (2012). Os resultados encontrados foram agrupados em quatro seções: igualdade, equidade e discriminação; planos educacionais e outros documentos oficiais, Diversidade sexual, Ideologia de gênero e questões LGBTQ; e Mulheres e feminismos. Percebeu-se que as questões de gênero encontram um tímido espaço na agenda pública, principalmente por conta do aumento da pressão dos grupos conservadores, mas que há avanços nas práticas de promoção da equidade e combate as práticas discriminatórias diversas.

Palavras-Chave: Políticas Públicas Educacionais. Gênero. Educação. 
Abstract. This article addresses the State of the Art of educational public policies that support gender issues in Brazil. It is a research in progress developed in the Graduate Program in Teaching of Sciences and Humanities (PPGECH) under the Federal University of Amazonas - UFAM, Humaitá Unit - IEAA. In this section we seek to make a literature review of research on educational policies related to gender issues in Brazil in the last five years. This is a bibliographic research, conducted from the database of journals of the Coordination for the Improvement of Higher Education Personnel - CAPES, with a time frame of five years (2016 to 2021), of qualitative approach, from the descriptors: educational policies and gender; gender and education. The analysis and discussion of the data were inspired by post-critical studies in education, based on authors who move between the fields of "post" prefixes, from Meyer and Paraíso (2012). The results found were grouped into four sections: equality, equity and discrimination; educational plans and other official documents, Sexual diversity, gender ideology and LGBTQ issues; and Women and feminisms. It was noticed that gender issues find a shy space in the public agenda, mainly because of the increased pressure from conservative groups, but that there are advances in practices to promote equity and combat various discriminatory practices.

Keywords: Public Educational Policies. Gender. Education.

\section{Introdução}

Nas últimas décadas, as questões de gênero têm assumido um papel de destaque na esfera educacional, o que pode ser percebido na quantidade de grupos de pesquisa sobre o assunto nas universidades, assim como de eixos temáticos em diversos eventos científicos realizados no Brasil, principalmente nesse período de pandemia vivenciado desde o ano de 2020, quando se multiplicaram o número de atividades remotas voltadas ao desenvolvimento acadêmico e profissional.

O objetivo deste levantamento é fazer uma revisão de literatura sobre as pesquisas em torno das políticas educacionais voltadas as questões de gênero no Brasil, nos últimos cinco anos, a fim de nortear a investigação sobre as políticas públicas da educação que norteiam as práticas pedagógicas com vistas ao empoderamento feminino, pesquisa em andamento junto ao Programa de Pós-graduação e Ensino de Ciências e Humanidades, da Universidade Federal do Amazonas.

Ao realizar o levantamento do estado da arte das políticas públicas em educação voltadas para as questões relacionadas ao gênero, faz-se necessário destacar que o contexto abarca uma demanda significativa de conceitos e significados, os quais precisam ser lidos e analisados sob uma lente desprendida de concepções prévias tomadas como absolutas.

Zanela (2012) destaca a necessidade de "olhar o outro, olhar o entorno, olhar para si" (p.169), dilatando as possibilidades, de modo a vislumbrar os novos arranjos sociais presentes na sociedade contemporânea. Esse olhar vai além do olho físico, pois somente assim daremos conta das "estereotipias, dos enrijecimentos, dos vieses de classe social, da etnia, de gênero, de construção cultural, dos enrijecimentos ontológicos e epistemológicos que caracterizam as leituras que fazemos da realidade" (p. 170).

Lemos e Rocha (2012, p. 182) destacam que a produção do conhecimento, do homem e do mundo deve ocorrer sob uma nova forma de pensar, sob novos contornos, visto que $\mathrm{o}$ ato de pensar "é um modo de resistência que faculta romper com o assujeitamento, efetuando deslocamentos simultaneamente na pesquisa e no pesquisador". 
Dentre os temas mais discutidos nas produções acadêmicas dos últimos cinco anos é possível citar as questões de gênero sob uma perspectiva cultural e social, em detrimento ao conceito estritamente biológico; a ideia de diversidade, partindo de um ponto de vista de um referencial historicamente constituído; as questões de igualdade, equidade e discriminação; o discurso presente nos documentos oficiais que norteiam a educação brasileira e a reformulação curricular brasileira.

Esses temas sugerem uma leitura e análise que permitam a visualização de novas nuances, a partir de reflexões que não estejam enrijecidas, mas abertas a novas descobertas, de modo a ler os "ditos e escritos", como proposto por Paraíso (2012), em procedimentos de montagem, remontagem, composição e recomposição.

Desse modo, a análise e discussões dos resultados alcançados estão inspirados nos estudos pós-críticos em educação, com aproximações teóricas baseadas nos estudos culturais e estudos de gênero, buscando estratégias que sugiram resistências às formas de subjugo e opressão, aos quais tem sido submetidos jovens estudantes dentro e fora de espaços escolares. Meyer (2018) defende a necessidade de que essas resistências

[...] mobilizem (ou possam mobilizar) indignação, coragem, esperança e ousadia tanto para denunciar a subtração de liberdade e driblar os silêncios impostos, como para experimentar e (re) inventar formas outras de re (des) dizer e re (des) fazer gêneros e sexualidades em currículos escolares e culturais. (MEYER, 2018, p.10).

Posto isso, espera-se com este levantamento fortalecer as reflexões sobre a necessidade de contemplar as questões de gênero na agenda de políticas públicas, principalmente na esfera educacional, visto ser a escola uma instituição de relevância social extrema, capaz de auxiliar na solidificação de uma estrutura contemporânea mais cidadã e democrática.

\section{Procedimentos metodológicos}

O presente levantamento do estado do conhecimento trata-se de uma pesquisa bibliográfica, de abordagem qualitativa, visto que se pretende refletir sobre crenças, valores e atitudes, a fim de encontrar pontos convergentes e divergentes entre os autores pesquisados.

A pesquisa foi realizada a partir da base de dados de periódicos da Coordenação de Aperfeiçoamento de Pessoal de Nível Superior - CAPES, com recorte temporal de cinco anos (2016 a 2021), a partir dos descritores: políticas educacionais e gênero; gênero e educação.

A escolha da base de dados se deu por conta do nível de importância e confiabilidade dos textos encontrados na plataforma, visto que a temática demanda uma seleção criteriosa, de pesquisas e pesquisadores comprometidos com educação e com as questões sociais em pauta.

Paraíso (2012) explica que os estudos pós críticos em educação mergulham no pensamento escolhido, a fim de separar conceitos e fazer diversos tipos de perguntas, as quais proporcionem interrogar, questionar o material analisado, fazer os sentidos multiplicarem-se, de modo que nos ajude a pensar diferente do que já fora pensado e fazer conexões inesperadas.

Foram utilizados como critérios de busca artigos revisados por pares, com retorno de 1.039 (mil e trinta e nove) trabalhos. Seguiu-se, então, a aplicação de filtros, tendo como critérios trabalhos em formato PDF, em língua portuguesa e fechou-se com o recorte temporal de 2016 a 2021. 
Dentre os artigos encontrados após todos os filtros, em um total de 68, foram selecionados 20 (vinte) trabalhos, a partir da análise dos resumos e dos resultados encontrados pelos autores, de modo a identificar quais se aproximavam do presente objeto de pesquisa e estivessem alinhados às políticas públicas e práticas pedagógicas em torno das questões de gênero. Os textos selecionados foram agrupados por temas de discussão, sendo distribuídos conforme se vê no quadro abaixo:

Quadro 01: Similaridades temáticas na pesquisa

\begin{tabular}{|l|l|l|}
\hline 1 & Igualdade, Equidade e discriminação & 6 artigos \\
\hline 2 & Currículo, Planos educacionais e outros documentos oficiais & 6 artigos \\
\hline 3 & Diversidade sexual, Ideologia de gênero e questões LGBTQ & 4 artigos \\
\hline 4 & Mulheres e Feminismos & 4 artigos \\
\hline
\end{tabular}

Fonte: Elaborado pelas autoras.

\section{Inquietações e reflexões propostas}

A organização das seções se deu a partir da observância das similaridades e/ou contradições percebidas ao analisar as pesquisas, notando-se que esses temas têm sido amplamente discutidos pelos pesquisadores que se interessam por questões de gênero no âmbito educacional. Nesse contexto, parte-se uma exposição dos resultados discutidos pelos autores, sob uma ótica que promova relações de igualdade, equidade e combata qualquer forma de discriminação.

Os conceitos de Currículo, Gênero e sexualidade abordados estão amparados nas definições de Paraíso e Caldeira (2018, p. 13), as quais defendem a discussão desses termos nas escolas, pois "podem desestabilizar, desordenar, estranhar, resistir, e fazer desejar. Esse trio pode fazer a diferença! Nas escolas, na cidade, na vida!".

Assim, Currículo será entendido como um território político e estético que não se pode controlar, usado para regulação, ordenação e, às vezes, territórios de escapes de todos os tipos (PARAÍSO; CALDEIRA, 2018). Em relação ao Gênero, deve ser entendido como uma teoria que explica os processos históricos e culturais nos quais foram construídas as ideias de masculino e feminino, sua normalização e hierarquia, levando em consideração as diversas possibilidades de "vidas vivíveis" (p.13). A sexualidade, por sua vez, as autoras definem como vivências de sensações, prazeres e desejos, os quais podem acarretar sofrimentos e exclusões, desencaixotar emoções e ainda fazer tremer as tentativas de controle do que elas chamam "de vida a jorrar" (p. 13).

De acordo com as autoras, as questões de gênero e sexualidade estão sendo incorporadas ao campo de estudos curriculares no Brasil de forma tímida. O pensamento feminista e as teorias de gênero, assim como o pensamento queer "instauraram modos de pensar bastante diferentes dos usuais no campo curricular, o que demonstrou mudanças de pensamentos, de leitura dos currículos, outras apropriações de abordagens, termos e conceitos. (PARAÍSO; CALDEIRA, 2018, p. 15). Com base nessa perspectiva, são propostas as reflexões das seções a seguir.

\subsection{Igualdade, Equidade e Discriminação}

Dentre os autores que abordam a temática desta sessão, iniciamos com Neto e Santos (2019), os quais discutem a educação em gênero e diversidade sexual na promoção da igualdade de gênero. Sua pesquisa objetiva compreender como a educação, pautada nas questões de gênero, pode auxiliar no reconhecimento das diferenças, promovendo a igualdade entre os gêneros, de modo a auxiliar na construção da cidadania. 
O texto chamou bastante atenção por especificar de forma clara seu sujeito de pesquisa, a mulher negra. É fato que é de suma importância esse recorte, visto ser que a mulher já vivencia vários tipos de limitações, isso se agrava ainda mais quando é negra, segundo os autores. É possível perceber dois pontos em destaque: a necessidade de envolver a escola na construção da cidadania, reconhecimento das diferenças e estímulo a práticas não discriminatórias. Para tal, os autores apresentam um levantamento histórico da concepção de cidadania e como ela tem sido incluída no contexto brasileiro e, principalmente na escola.

Sobre o conceito de diversidade, recorre a Louro (2011) para destacar que a ideia de diversidade tem sido posta com base em um referencial que se perpetua na sociedade, no geral, o homem branco, de classe média urbana, heterossexual e cristão, o que transmite a ideia de que o que foge disso é o diverso.

Compactua com essa ideia, Guizzo (2016), ao afirmar que o entendimento de gênero não deve estar vinculado somente à ideia do aspecto biológico, mas ressalta a importância de estarmos atentos às questões sociais, geográficas e culturais envolvidas neste conceito.

Os grupos que emergiram a partir da década de 60, os quais lutavam para que seus direitos fossem respeitados, ganharam visibilidade no cenário educacional, cito os indígenas, pessoas com deficiência, negros/as, mulheres e não heterossexuais (GUIZO, 2016). A principal pauta sempre foi que fossem tratados como iguais, que suas necessidades fossem incluídas, que suas formas de ver e pensar fossem respeitadas. Esse pensamento pareceu recorrente nos textos em estudo.

Ribeiro, Bonamico e Martinic (2020) analisam duas iniciativas: a política de educação para os anos iniciais do ensino fundamental de Marília, município do estado de São Paulo, e o Programa de Alfabetização na Idade Certa (Paic), do estado do Ceará. A partir de um estudo aprofundado sobre políticas públicas, apresenta uma possibilidade de atender o que recomendam os documentos norteadores da educação brasileira em relação a uma educação que promova a equidade, garanta o acesso e permanência de todos na escola, sem qualquer tipo de discriminação.

As políticas desenvolvidas apresentaram resultados satisfatórios, mapeados nas avaliações externas dos sistemas de ensino de ambas as cidades e que resultaram em melhorias na qualidade do ensino e nas condições de equidade, apesar de não estimular de modo significativo a autonomia das escolas e suas equipes pedagógicas.

Outro estudo ganhou destaque por trazer um relevante dado sobre o desempenho de meninas brancas em relação a meninas negras e pardas. Ernica e Rodrigues (2020) fizeram um levantamento das desigualdades vislumbradas nas metrópoles, em especial na cidade de São Paulo, onde se percebeu desigualdades agudas. Nele aponta-se que houve avanços em relação à identificação das desigualdades educacionais, entretanto ainda existe uma carência de estudos sobre desigualdades educacionais por gênero e raça, sendo mais comum analisá-las em virtude da classe social. Os resultados da pesquisa mostram que

As vantagens escolares das meninas brancas e pardas, sobretudo as de maior NSE, são persistentes entre as regiões da cidade porque esses grupos reuniriam os atributos mais valorizados e rentáveis no espaço escolar, permitindo-lhes receber as melhores oportunidades educacionais. Os meninos brancos e pardos vêm a seguir. As meninas pretas só se beneficiariam de melhores oportunidades educacionais em distritos mais equitativos, qualquer que seja o seu nível de aprendizagem. (ERNICA; RODRIGUES, 2020, p.15).

Para que essas desigualdades sejam superadas, é importante que haja uma sensibilização de toda a comunidade escolar, a fim de desenvolver um trabalho coletivo 
que promova reflexões incansáveis. Além disso, o professor precisa buscar práticas pedagógicas que favoreçam a discussão sobre o assunto, como propuseram Klug, Lima e Lebedeff (2016), as quais utilizaram a leitura em sala de aula como mediadora da construção da igualdade de gênero, a partir das obras de Marcio Ramos e Marina Colasanti. Na proposta apresentada, buscou-se apresentar aos alunos produções que abordassem as questões de gênero, a fim de que fossem confrontados e pudessem expor suas ideias, através dos debates e da escrita sobre as suas memórias sobre o assunto.

Essa prática contou com sequência didática bem delimitada, na qual se estabeleceu três passos: a sondagem oral com os estudantes sobre os temas que consideravam relevantes ao se discutir questões de gênero; produção escrita, em diferentes gêneros textuais, sobre o que sabiam sobre o assunto, apresentando fatos observados em jornais, redes sociais ou mesmo experiências pessoais; discussão sobre o vídeo e o conto, conduzidos pela professora; finalmente, a produção dos estudantes, agora com o olhar refinado, a partir das atividades realizadas em sala.

A proposta parece contribuir significativamente com a promoção da igualdade e combate a qualquer prática de discriminação, pois pode incutir nos educandos "ideias que possam não só fazê-los repensar os preconceitos existentes no nosso cotidiano, como também refletir sobre as práticas que continuarão exercendo em suas vidas enquanto homens e mulheres que tomarão as rédeas de suas vidas" (KLUG, LIMA E LEBEDEFF, 2016, p. 106). Os resultados da pesquisa apontaram efeitos consideráveis na postura e no discurso dos envolvidos, os quais devem ser vistos como fatores a serem considerados ao se pensar em práticas pedagógicas, pois podem proporcionar

a mudança de opinião, a fundamentação dos argumentos para respostas, a eliminação de respostas evasivas ou repletas de senso comum, a não repetição de clichês, a não conformação ou aceitação de crimes contra os direitos humanos, a indignação quando uma mulher é agredida ou morta sem contar quando são vítimas das violências simbólicas e psicológicas. (KLUG, LIMA E LEBEDEFF, 2016, p. 106).

Desse modo, ressalta-se a importância de olhar com atenção as questões que envolvem igualdade, equidade e discriminação no contexto escolar, numa perspectiva de se envolver com a situação em análise, de modo a intervir na realidade observada, como propõe Zanella (2012, p.170) "ver não como atividade do olho nu, esse uma quimera, mas sob o prisma de sua refração. Eis o motivo pelo qual se faz importante não se conformar com o que os nossos olhos veem, mas sim dilatar suas possibilidades." É importante exercitar esse novo olhar sobre o outro e suas peculiaridades, ampliando as possibilidades de reconhecimento, respeito e valorização das diferenças.

\subsection{Currículo, Planos educacionais e outros documentos oficiais}

Esta seção se volta à discussão sobre alguns documentos legais que envolvem as questões de gênero. Percebe-se entre os artigos visitados a preocupação com a gradativa retirada do termo gênero de vários documentos, como os Parâmetros Curriculares Nacionais, diversos planos municipais, estaduais e do plano nacional de educação, e, mais recentemente, da Base Nacional Comum Curricular.

Ramalho e Vieira (2018) apresentam uma investigação sobre a construção do Plano Nacional de Educação 2014-2024, mostrando as diferentes formas de tratar a temática sobre gênero na estruturação do documento. A partir da análise do Projeto de Lei 8.035/2010; Lei 13.005/2014; e documento suplementar desta, os autores declaram ser necessária a realização de mais pesquisas relacionadas às políticas educacionais direcionadas ao gênero "para embasar, cada vez mais, a compreensão acerca do assunto, 
procurando atenuar as violências que o receio do desconhecido pode vir a trazer" (RAMALHO E VIEIRA, 2018, p. 179).

Essa é uma realidade notória em diversos ambientes escolares, visto ainda ser possível encontrar educadores que se recusam a abordar essas questões em sala de aula, ainda que como possibilidade de tema transversal. Brandão e Lopes (2018) discutem as premissas que envolvem o debate público no Brasil sobre a inclusão dos conteúdos relativos ao gênero e à sexualidade no Plano Nacional de Educação.

A pesquisa revela que a "perspectiva de construção social do gênero e da sexualidade é questionada por ser considerada disruptiva à família, para certos segmentos religiosos e políticos, não devendo ser tratada na escola" (BRANDÃO E LOPES, 2018, p. 100). Esse pensamento tem sido determinante para que a abordagem da temática ainda seja vista com receio, ocasionando uma lacuna na tarefa de sensibilização acerca da problemática que a questão envolve.

Discute-se, ainda, a questão das discriminações e violências sofridas por estudantes, devido ao estigma e desigualdade de gênero persistente nos espaços escolares. A retirada das categorias sociais no art. 2, inciso III na terceira diretriz, a qual mencionava "superação das desigualdades educacionais, com ênfase na promoção da igualdade racial, regional, de gênero e de orientação sexual" (Brasil, 2012, p. 1), para o texto final resumitivo, que sugere apenas "erradicação de todas as formas de discriminação" (Brasil, 2014 p. 1), representa um retrocesso em relação a luta social para efetivação dos direitos assegurados pela constituição federal, conforme Brandão e Lopes, 2018:

Não incentivar a discussão de gênero e sexualidade na escola contribui para a persistência das desigualdades e discriminações sociais, bem como para expressões de violência, no espaço escolar ou em outros ambientes sociais. $O$ debate sobre gênero e sexualidade na escola pode diminuir 0 machismo e a misoginia, conduzir à promoção da igualdade de gênero e da diversidade sexual, por meio do aprendizado do convívio com diferenças socioculturais. Assim, evitam-se situações de sofrimento, adoecimento e abandono escolar por razões que não competem somente a adolescentes. (BRANDÃO e LOPES, 2018, p. 102).

Parte desse retrocesso se deu por conta da atuação alarmista da mídia que, à ocasião dos debates para aprovação do plano, manteve uma postura tendenciosa, o que fortaleceu a instauração de um pânico moral (BRANDÃO E LOPES, 2018, p.106). Informações como a distribuição de "kit gay" e a implementação do que chamaram de ideologia de gênero, mobilizou muitos segmentos conservadores nas redes sociais e acabaram atrasando, por quase quatro anos a aprovação do texto final do plano. Os autores sintetizam que

É necessário ultrapassar as concepções normativas a fim de garantir a promoção da igualdade de gênero e o fim das discriminações sexuais. As influências sociais religiosas e de matrizes conservadoras são fortes intervenientes na aprovação das políticas públicas brasileiras, ressaltando as dificuldades de se afirmar o país como um estado laico. É preciso superar muitas barreiras para se afirmar os direitos humanos, garantindo assim, a democracia no Brasil. (BRANDÃO e LOPES, 2018, p. 117).

Em meio a esse cenário, Furlin (2021) destaca que o Brasil conseguiu implementar algumas políticas educacionais com perspectivas de gênero no governo de Dilma Rousseff e fez um estudo comparativo com as políticas do governo chileno de Michelle Bachelet, cujos resultados apontam especificidades de disputas na agenda pública e nas políticas implementadas vinculadas aos contextos cultural, político e social desses países. 
Segundo o estudo, nota-se que o Brasil, da mesma forma que o Chile, seguiu a tendência latino-americana para formulação de políticas públicas, "centrada na igualdade de oportunidades, depois para a equidade de gênero com base nos direitos, implementadas a partir da estratégia da transversalidade de gênero em todas as políticas do Estado" (FURLIN, 2021, p. 134).

A autora justifica o interesse pela pesquisa destacando que ambas, Dilma Rousseff e Michele Bachelet, se tornaram presidentes de seus países e possuem um histórico semelhante na busca pela defesa dos direitos das mulheres e pela promoção de políticas que promovam a equidade de gênero. Desse modo, justifica que

É fundamental que as mulheres, como atrizes sociais, estejam representadas na arena política, lugar das decisões acerca das políticas de redistribuição e de reconhecimento, como forma de fazer justiça social às diferentes mulheres que, historicamente, foram privadas do acesso aos bens materiais e simbólicos, por convenções sociais da cultura patriarcal. (FURLIN, 2021, p. 136).

Destaca-se no artigo a contextualização das políticas de gênero no cenário brasileiro e logo após no latino-americano, a transversalidade do gênero nas políticas educacionais, como no plano nacional de educação, bem como os mecanismos criados para assegurar essa transversalidade na gestão das presidentes em questão.

Dentre os principais resultados apontados por Furlin (2018), destaca-se a inserção das políticas transversais de gênero para a educação, a qual viabilizou a redistribuição e o reconhecimento, criando estratégias para ampliar o acesso das mulheres e da população LGBT a lugares que outrora era dominado por homens, em sua maioria, brancos, classe média alta e heterossexuais.

Vieira e Gonzalez (2019) dedicam-se à análise do Volume 10, dedicado a apresentar o tema transversal da "Orientação sexual", nos Parâmetros Curriculares Nacionais, pois consideram o documento como basilar na introdução do tema na educação brasileira. No texto, realizam "reflexões sobre as relações de força em curso que sustentam os discursos mais biológico-higienistas e moral-tradicionalistas nos documentos político-pedagógicos em vigência no País" (VIEIRA E GONZALES, 2021, p.154).

É importante destacar que a omissão das reflexões de gênero no ambiente escolar, segundo as autoras, fere os fundamentos do Estado Democrático de Direito, assim como os princípios norteadores da educação, como o compromisso com a cidadania, respeito aos direitos humanos, repúdio à discriminação de qualquer tipo, acesso a condições de vida digna, respeito mútuo nas relações interpessoais, públicas e privadas; garantia a todas as pessoas da mesma dignidade e possibilidade de exercício de cidadania, considerandose diferenças étnicas, culturais, regionais, de gênero, etárias, religiosas; corresponsabilidade pela vida social (BRASIL, 1998).

O texto final da Base Nacional Comum Curricular, documento de caráter normativo que define o conjunto orgânico e progressivo de aprendizagens essenciais que todos os alunos devem desenvolver ao longo das etapas e modalidades da Educação Básica, suprimiu conceitos importantes como "identidade de gênero" e "orientação sexual". Conforme Antas e Arantes (2019), esse cenário deve ser discutido com atenção, a fim de que "desigualdades histórica, social e culturalmente instituídas não sejam perpetuadas, mantendo grupos em situação de privilégio em detrimento de outros que, no decorrer na História, foram colocados em situação de exclusão" (ANTAS E ARANTES, 2019, p.02).

Essa supressão refletiu na formulação dos planos municipais e estaduais de educação, os quais foram muito confrontados e acabaram também suprimindo esses conceitos dos documentos, o que interfere na formulação e implementação de políticas 
públicas direcionadas às questões de gênero e sexualidade, interferindo, acima de tudo no contexto escolar.

Carvalho (2020) afirma que os professores não devem se eximir da inserção das reflexões sobre gênero em suas aulas, visto que os segmentos conservadores conseguiram suprimir esse conceito dos documentos, mas não o podem retirá-lo das convicções ideológicas, da comunidade escolar e comunidade acadêmica. Segundo ele, o profissional de educação deve manter uma postura de resistência, frente às tentativas de limitação sugeridas pela "Educação maior", posto que é papel da escola promover empoderamento às minorias.

Por fim, reforça-se que existe uma preocupação consensual entre os pesquisadores que se voltam a pensar uma educação igualitária, que se lute pela permanência das questões de gênero na agenda de formulação das políticas públicas educacionais, visto ser imprescindível que essa demanda esteja latente nos planejamentos das ações e práticas pedagógicas cotidianas, de modo a intervir na realidade de inúmeros estudantes e demais membros da comunidade escolar, vítimas dos mais variados tipos de preconceito e discriminação.

\subsection{Diversidade sexual, Ideologia de gênero e questões LGBTQ}

O subtítulo acima prescrito pretende nomear o presente bloco reservado a suscitar reflexões sobre esses itens que se mantêm na lista dos mais complexos de se abordar em sala de aula, visto a escola estar inserida em uma sociedade que apresenta fortes traços conservadores (FREIRE, 2018). É importante destacar que as rotulações inapropriadas em relação às diferenças só serão atenuadas mediante uma discussão reflexiva, exaustiva e continuada.

Dentre os artigos selecionados que abordam essas discussões, pôde-se perceber uma determinada sincronia sobre a construção de uma escola democrática, acessível a todos, somente quando esta estabelecer um diálogo coerente entre o que propõem os documentos norteadores e a realidade vivenciada no contexto escolar.

As questões de identidade de gênero e a presença marcante de conceitos e ideais comportamentais ligados a princípios da heteronormatividade são questionados por pesquisadores (FREIRE, 2018; BORGES, 2018) que têm se dedicado a estudar e difundir os resultados dos mais diversos grupos de estudos nas universidades brasileiras. Freire (2018, p.33) faz uma análise crítica em torno da ideologia de gênero, que ganhou força nos últimos anos no Brasil. A autora afirma que o "olhar de estranhamento para o/a outro/a é basilar no modo como a manipulação desse discurso coloca a centralidade da heteronormatividade do gênero na política de educação".

Para a autora, a justificativa para o fortalecimento dessa ideologia se assenta no pensamento de que o objetivo de incluir essa pauta nos currículos escolares seria uma forma de atentado ao que se tem estabelecido biologicamente aos corpos físicos e ao uso da sexualidade, tornando o tema um risco para a confusão comportamental dos jovens, podendo levá-los a uma perda de identidade.

Freire (2018) busca desconstruir esse pensamento tomando por base os estudos de Judith Butler e Guacira Louro, as quais defendem que as identidades de gênero não são fixas ou imutáveis, mas sim, fruto de um caráter performativo, não havendo verdadeiro ou falso, certo ou errado, devendo, portanto, ser discutida na escola sem a intenção de homogeneização, a fim de não eliminar os que não se encaixam no padrão heteronormativo. Nesse sentido, "a manipulação do discurso ideologia de gênero quer atribuir um humano idealizado numa representação de homogeneidade imaginária" (FREIRE, 2018, p. 40). 
Destaca-se o agravamento da propagação desse pensamento devido ao fato de que legitima a violência e a discriminação aos sujeitos que não se enquadram em um modelo preestabelecido de feminilidade ou masculinidade, ou ainda ideológico. Borges (2018) chama essa postura de política de aversão a abordagem das questões de gênero e sexualidade nas escolas.

O autor cita que as diferenças são marcas da humanidade, fazem parte da criatividade humana, desse modo, o que deveria ser o foco da discussão e o que deveria realmente importar seria "a educação para o diálogo e a compreensão das diferenças, não apenas buscando entender como elas surgem ou como se estabelecem, mas proporcionando formas de convívio com igualdade de condições e sem discriminações" (BORGES, 2018, p.10-11).

Machado, Graupe e Locks (2019) analisam as políticas públicas voltadas para a população LGBTTT: o Programa Brasil sem Homofobia (2004), Plano Nacional de Promoção da Cidadania e Direitos Humanos de Lésbicas, Gays, Bissexuais, Travestis e Transexuais (2009) e o Plano Nacional de Educação (2014-2024) e apresentam resultados que apontam a discriminação sofrida por esse público, assim como a clara invisibilidade a que foram sujeitados desde 2018, pelo atual governo.

A pesquisa aponta que, apesar de os referidos programas objetivarem a equiparação de direitos, o combate à violência e à discriminação homofóbicas, respeitando a especificidade de cada um desses grupos populacionais, ainda não é possível a constatação da real efetivação desses direitos, os quais já estão previstos na constituição, mas encontram inúmeras barreiras para que sejam efetivados.

Um forte exemplo citado é o Programa Brasil sem Homofobia, de 2019, criado pelo Ministério da Educação. Seu objetivo era promover uma série de políticas e ações voltadas ao combate da Homofobia nas escolas e previa a distribuição de material didático específico, como cartilhas, folders e vídeos, a fim de proporcionar sensibilização e promover um espaço de discussões e formações sobre o tema.

Segundo os autores, o programa foi interpretado de forma equivocada por diversos segmentos tradicionais e conservadores, os quais entenderam que essas ações intentavam desvirtuar as crianças e adolescentes, obrigando-os a concordar que as opções sexuais em questão deveriam ser tomadas como ideais ou padronizadas, surgindo a partir desse contexto, o que ficou conhecido como "kit gay", expressão utilizada para descrever o material didático que, há época, pretendia-se distribuir. Sobre esse fato, Machado, Graupe e Locks (2019) declaram que

O "kit de Combate à Homofobia" foi vetado pela presidenta Dilma Rousseff no dia 25 de maio do mesmo ano (2011). Salientamos que o referido material poderia ter sido um marco no fazer da educação brasileira, por ser didático e conter subsídios pedagógicos para se trabalhar a prevenção e o combate das violências contra as pessoas LGBTTT nas escolas públicas. A decisão da então Presidenta foi tomada após uma reunião com deputados da chamada bancada religiosa e conservadora. (MACHADO; GRAUPE; LOKS, 2019, p. 35).

Outro ponto de alerta apontado na pesquisa, diz respeito ao avanço do conservadorismo proposto pelo projeto Escola Sem Partido, o qual propõe uma escolarização sem doutrinação ideológica, defendendo uma proposta de educação brasileira conservadora. A Conferência Nacional dos Bispos do Brasil e a Frente Parlamentar Evangélica foram as principais responsáveis por suscitar os questionamentos sobre as questões de gênero, difundindo a ideia da tentativa de implementação da ideologia 
de gênero, fato que fortaleceu a iniciativa da escola sem partido. (MACHADO; GRAUPE; LOKS, 2019).

Os primeiros a proporem a ideia da Escola sem partido foram os representantes políticos membros da família Bolsonaro, os quais são conhecidos pelo alinhamento ideológico com a extrema direita do país (MACHADO; GRAUPE; LOKS, 2019). Na concepção proposta, cujo pretexto é defender os estudantes de serem influenciados pelos professores, nota-se claramente o pensamento bancário da educação, tão criticado por Paulo Freire. Percebe-se claramente que a educação não é vista como capaz de formar cidadãos críticos, capazes de entender as diversas manifestações culturais e sociais do seu entorno, dessa forma, necessitando de um tutor para lhes apresentar o caminho "certo" a seguir. (MACHADO; GRAUPE; LOKS, 2019).

Destarte esse pensamento conservador, Vieira e Lage (2017) apresentam uma pesquisa feita em cinco municípios do agreste pernambucano, na qual constataram que alguns cenários escolares fogem aos padrões heteronormativos estabelecidos histórica e culturalmente. Essa desconstrução tem sido estabelecida principalmente pelo envolvimento da comunidade estudantil, que tem provocado diversos tipos de incômodo, de intensidades e níveis diferenciados. Percebe-se nos resultados apresentados pelos autores, que a tentativa de silenciamento da temática representa uma espécie de "sintomas de uma neurose doentia que se manifesta através de uma violenta repressão e interdição" (VIEIRA e LAGE, 2017, p.591). Os professores destacam que dentre suas maiores dificuldades ainda permanecem a carência curricular e/ou falta de diretriz. A única forma de superar essa tentativa de invisibilização é investir no empoderamento de toda a classe trabalhadora da educação e todos os setores envolvidos no processo escolar.

Roseno e Silva (2017) afirmam que os movimentos feministas orientaram suas lutas contra os ideais propostos por esse movimento silenciador, aliando forças no combate às desigualdades perpetuadas pelo patriarcado, como machismo, o sexismo, racismo e todas as demais manifestações preconceituosas estabelecidas. Desse modo, revela-se a necessidade de um maior envolvimento dos grupos sociais no acompanhamento das etapas percorridas por essas políticas, visto que "o chão da escola deve servir para a superação das opressões, além de permitir a emersão de sujeitos antes invisibilizados por processos históricos discriminatórios" (ROSENO e SILVA, 2017. p. 14).

Todos os textos lidos e expostos comungam do pensamento que as questões de gênero devem ser estudadas de forma respeitosa, séria, crítica e reflexiva, proporcionando aos educandos e demais membros da comunidade escolar, a possibilidade de vivenciarem uma educação transformadora. Desse modo, espera-se que a prática educacional estimule a emancipação dos sujeitos, tanto como cidadão quanto como profissional, de modo a viver conforme suas interpretações da vida e do seu modo de ser.

\subsection{Mulheres e feminismos}

Este campo busca discorrer sobre alguns temas voltados a pauta feminista presentes nas publicações acadêmicas recentes, envolvendo a política educacional brasileira. Apesar de ser uma discussão muito ampla, o debate aponta algumas interseccionalidades, as quais são fundamentais para uma reflexão mais sensata e produtiva. (FIGUEIREDO; MARTINS, 2020). Dentre os itens analisados, destaca-se o feminismo interseccional, a oposição entre feminismo e machismo e o combate às práticas sexistas e misóginas na escola.

Parte-se do pensamento de que é necessário romper com o silêncio a que as mulheres foram submetidas ao longo dos anos, tornando-as reféns de uma sociedade marcada por um patriarcalismo que se sustenta após gerações (FIGUEIREDO; MARTINS, 2020). É notório que o movimento feminista está ganhando espaço significativo, em diversos contextos e cenários, o que tem resultado em conquistas relevantes em prol da 
igualdade de gênero, respeito às questões étnico-raciais e valorização da diversidade. Ainda assim, segundo os autores, há muito que avançar e espaços a firmar território de resistência, como na escola e todos os espaços a ela ligados.

Figueiredo e Martins (2020) defendem que o feminismo representa um movimento que vai além do social, visto ser também um movimento político, que discute, dentre outros pontos, "a desconstrução dos padrões machistas de uma sociedade patriarcal [...] sua base política deve ser antirracista, combatente da LGBTfobia e as diferentes formas de opressão que recaem sobre os grupos socialmente excluídos. (FIGUEIREDO e MARTINS, 2020, p. 335). Nesse sentido, a interseccionalidade surge como indispensável na pauta desse discurso.

Por se tratar de um movimento formado por diferentes mulheres em busca de emancipação social, a qual possibilite a saída da condição subalterna a que têm sido subjugadas, essas mulheres possuem diferentes lugares de fala, ou seja, diferentes origens, realidades e opressões, por exemplo, mulheres, negras, indígenas, homoafetivas, nortistas (assim como outras diversidades regionais brasileiras), de classes sociais diversas e com diferentes graus de instrução e escolaridade (AKOTIRENE, 2020). Essa pluralidade não permite analisar o movimento sob uma ótica de reivindicações homogêneas, não havendo um molde que comporte toda a pauta do movimento.

Figueiredo e Martins (2020) trazem à discussão a necessidade de inclusão da pauta das mulheres negras no movimento feminista, que explodiu nos anos 70 , a fim de evidenciar que suas opressões divergiam daquelas vivenciadas pelas mulheres brancas, em sua maioria de classe média alta e heterossexuais, o que foi imprescindível para maior visibilidade da luta das diversas categorias, como as de classe, gênero e raça contribuindo para uma compreensão mais estruturada da exclusão das mulheres, em suas mais diversas expressões.

É a pauta do racismo trazida pelas mulheres negras, a lesbofobia trazida pelas mulheres lésbicas, as diferentes identidades de gênero, tal qual a transgeneridade das mulheres trans e a opressão classista que recai sobre as mulheres pobres. Essas experiências não chegam de forma isolada $e$ por isso não podem ser olhadas de forma desconexa, o que demanda o entendimento da necessidade de uma vertente teórica/metodológica e de uma prática feminista que dialogue e combata todo tipo de opressão sofrida pela mulher, que se unifica no gênero, mas não permanece apenas nele. (FIGUEIREDO e MARTINS, 2020, p. 337).

Esse conceito de interseccionalidade ${ }^{1}$ tem se tornado basilar nas questões que envolvem discussões de gênero, étnico-raciais e diversidade (AKOTIRENE, 2020), pois auxilia na desconstrução do pensamento de que as opressões são ocasionadas por fatores únicos, isolados, frisando que existe um cruzamento de subordinações que deve ser identificado, questionado e superado, mas para isso, é preciso entender a interseccionalidade como "uma teoria, forma de enxergar a realidade, mas também como uma metodologia para interpretar e intervir no mundo" (FIGUEIREDO e MARTINS, 2020, p. 335).

Surge então, nesse contexto, outro conceito relevante na busca pelo empoderamento feminino e combate às opressões: a sororidade, ligada à ideia de compromisso partilhado por mulheres subjugadas, a fim de acabar com as injustiças do patriarcado. (AKOTIRENE, 2020). Essa luta solidária e conjunta enfraquece as atitudes

\footnotetext{
${ }^{1}$ A interseccionalidade visa dar instrumentalidade teórico-metodológica à inseparabilidade estrutural do racismo, capitalismo e cisheteropatriarcado produtores de avenidas identitárias em que mulheres negras são repetidas vezes atingidas pelo cruzamento e sobreposição de gênero, raça e classe nos aparatos coloniais. (AKOTIRENE, 2020, p.19).
} 
sexistas e atua diretamente contra a misoginia, estabelecendo uma aliança entre o feminismo acadêmico, científico e/ou escolar, e a ação política.

Figueiredo e Martins (2020) pontuam como fator de discussão de extrema relevância as questões binárias, ainda predominantes na fala e nas práticas escolares, sem considerar as subjetividades contidas no ser masculino e ser feminino, visto ser possível perceber diversas possibilidades de se performar o gênero na contemporaneidade. Silva e Costa (2019) dispõem o resultado de uma pesquisa realizada em uma escola de educação básica, visando problematizar a permanência de inúmeros padrões sexistas na escola e como a escola pode trabalhar para desconstrução desse pensamento. Os autores reforçam que a escola vai muito além da missão de socialização de conhecimentos, ela deve produzir sentidos nos mais diversos aspectos da vida. As ações pedagógicas devem ser pensadas como dispositivos carregados de significações que irão afetar a formação de seus alunos.

Ao analisar o discurso dos sujeitos entrevistados, Silva e Costa (2019) perceberam a presença marcante de concepções sexistas, principalmente ao se referir ao que se espera do comportamento das meninas e dos meninos. Por diversas vezes, membros da comunidade escolar citaram que as meninas apresentavam um comportamento fora do esperado; brincavam, falavam e por vezes até brigavam como meninos, muito diferente do que se via no passado, quando elas eram vistas como seres angelicais, dóceis e que "não davam trabalho". Essa impressão relatada pelas educadoras entrevistadas indica a falta de entendimento ou de conhecimento sobre a existência de diferentes feminilidades e expressa claramente que o cenário escolar em estudo segue alicerçado em obediência a normas, na organização e submissão, reforçando um padrão opressivo. (SILVA e COSTA, 2019, p.65).

$\mathrm{Na}$ pesquisa, esse pensamento foi reiterado pela gestora da escola, que associou esse "comportamento inadequado" das meninas às lutas feministas por igualdade e maior abertura para lidar com temas voltados a liberdade sexual e trabalho fora do lar, destacando, inclusive, que as mulheres da atualidade não estão merecendo respeito. Silva e Costa (2019) confrontam esse pensamento exposto pela gestora justificando que ela desconhece a base da luta feminina, forjada em princípios de equidade, liberdade (inclusive sexual) e a ruptura com a estrutura machista, a qual perpetuou esse pensamento de que 0 respeito a mulher está condicionado ao bom comportamento.

Por outro lado, na mesma pesquisa, uma docente entrevistada expressou o que se espera nessa luta (SILVA; COSTA, 2019). Ela afirmou que acredita ser possível o fortalecimento da identidade feminina, através da sensibilização e estímulo à busca por maior espaço e autonomia na sociedade. Para ela, a escola deve mostrar às crianças as oportunidades existentes e oferecer ferramentas que as tornem acessíveis, através de uma educação menos autoritária, mas dotada de compromisso e responsabilidade (SILVA e COSTA, 2019). É preciso investir em uma educação menos limitadora às mulheres e suas aspirações, de modo a alcançar a emancipação.

A investigação apontou que a família também possui um papel de extrema relevância nesse contexto, visto que as primeiras noções de masculino e feminino são desenhadas no convívio familiar. É importante dialogar sobre as questões de cores, rosa e azul, de brinquedos e brincadeiras, boas maneiras, dentre outros (SILVA e COSTA, 2019). Destacou-se, ainda, que muitas famílias se sentem desorientadas na hora de abordar temas sobre a sexualidade e gênero e por isso, esperam que a escola se encarregue disso, posto que se encontram submersos em uma criação cercada de tabus, nos quais evita-se esses assuntos. Outras famílias acham inaceitável repassar esses temas polêmicos para os professores doutrinarem seus filhos, levando a pauta a um patamar de conflitos, evitado por muitos educadores. 
Silva e Costa (2019) finalizam sugerindo que somente após o momento em que os profissionais de educação estiverem formados adequadamente, com instrução necessária a entender a necessidade do planejamento do trabalho pedagógico que contemple os conteúdos e discussões sobre o gênero, sexualidade e diversidade, haverá maior construção identitária, livre de preconceitos ou desconhecimento.

Por outro lado, é possível desprender que a prática de projetos e práticas pedagógicas podem proporcionar uma perturbação nas certezas já estabelecidas, de modo a desconstruir um novo posicionamento acerca das posturas femininas, baseadas em metodologias alternativas. Barreto et all (2019) reitera que as instituições escolares estão inseridas em uma cultura fortemente androcêntrica, em uma lógica urbana, capitalista e de mercado, a qual se utiliza da linguagem como instrumento de poder, capaz de perpetuar práticas opressoras.

\section{Considerações finais}

Ao nos debruçarmos para fazer um levantamento sobre o Estado da Arte das políticas públicas educacionais brasileiras que contemplam as questões de gênero, não há como não ser afetado pelo grau tão elevado da importância de tal demanda. O pesquisador engajado na pauta da pesquisa "desponta a centralidade nos saberes, nas técnicas e nas verdades [...] experimentar afetos sinaliza a enunciação de outras formas de agir, a partir dos modos de expressão que vamos percorrendo. (LAZZAROTTO; CARVALHO, p. 23). É preciso investir em uma educação menos limitadora às mulheres e suas aspirações, de modo a alcançar a emancipação.

Cada educador deve entender seu papel diante dos obstáculos presenciados no cotidiano escolar, os quais são vislumbrados nas diversas modalidades de ensino da educação básica e superior, cabendo a ele atuar com uma postura de resistência ante a falta de prioridade das questões das minorias no contexto da formulação de políticas públicas.

Pesquisar, questionar, refletir, discutir incansavelmente está entre as possibilidades de alcançar os atores diretamente ligados a pauta das questões de gênero. Para se consolidar uma escola cidadã, na qual o respeito e a tolerância sejam o lema da vivência e das práticas pedagógicas, não é possível permanecer calados, antes, porém, é preciso conhecer as formas de reivindicação, de participação pública e de se fazer ouvir a voz dos oprimidos, somente assim, o ambiente escolar promoverá o desenvolvimento pleno do estudante cidadão.

No mais, acentua-se a urgência em ponderar essa revolução emancipatória tão almejada por meninas, mulheres, estudantes, educadoras, mães e demais membros da comunidade escolar e sociedade em geral, a qual é um requisito basilar para romper com o silêncio que tem perturbado inúmeras vítimas dos mais variados tipos de opressões na contemporaneidade.

\section{Referências}

AKOTIRENE, Carla. Interseccionalidade. São Paulo: Sueli Carneiro. Editora Jandaíra, 2020.

ANTAS, Raquel; ARANTES, Adlene. Supressão do conceito de gênero em documentos de educação no Brasil: debates e contexto. Cocar. V.13. N. 26. Mai./Ago./ 2019 p. 393-407. 
BARRETO, Giovana Carla (org). Gênero na educação e educação de gênero: a invisibilidade da mulher apesar de principal protagonista. Vozes e diálogo. Itajaí, v.18, n.02, jul-dez 2019.

BRANDÂO, Elaine; LOPES; Rebecca. "Não é competência do professor ser sexólogo" O debate público sobre gênero e sexualidade no Plano Nacional de Educação. Civitas, Porto Alegre, v. 18, n. 1, p. 100-123, jan.-abr. 2018.

BRASIL, PCN - Secretaria de Educação Média e Tecnológica. Parâmetros Curriculares Nacionais. Brasília: MEC/SEF,1997.

BORGES, Rafaela Oliveira; BORGES, Zulmira, Newlands. Pânico moral e ideologia de gênero articulados na supressão de diretrizes sobre questões de gênero e sexualidade nas escolas. Revista Brasileira de Educação, v. 23 e230039 2018, Disponível em: https://www.scielo.br/j/rbedu/a/PK43y8kghf9JDty4pftJS4n/?lang=pt. Acesso em: 12/03/2021.

BUENO, André da Silva; ESTACHESKI, Dulceli Tonet (Orgs.). CREMA, Everton Carlos. Gênero, educação e sexualidade: reconhecendo diferenças para superar (pre)conceitos. Uberlândia: Ed. dos Autores, 2016.

CARVALHO, Matheus. A base nacional comum curricular e sexualidade: crítica e resistência. Pesquisar, Florianópolis, v. 7, n. 13, Ed. especial: SELIGeo, p. 89-100, jun. 2020. Acesso em: 31/08/2021. Disponível em: https://periodicos.ufsc.br/index.php/pesquisar/article/view/74858.

ERNICA, Maurício; RODRIGUES, Erica. Desigualdades educacionais em metrópoles: território, nível socioeconômico, raça e gênero. Educ. Soc., Campinas, v. 41, e228514, 2020.

FIGUEIREDO, Priscila; MARTINS, Valéria. O Feminismo Interseccional na articulação do saber acadêmico e da ação política: reflexões a partir da experiência de um coletivo feminista. Revista do Programa de Pós-Graduação em Relações Étnicas e Contemporaneidade. ISSN: 2525-4715 -Ano 2020, Volume 5, número 10, Julho Dezembro de 2020. Acesso em: 10/09/2021. Disponível em: https://periodicos2.uesb.br/index.php/odeere/article/view/6780/5453.

FREIRE, Priscila. Ideologia de gênero e a política de educação no Brasil: exclusão e manipulação de um discurso heteronormativo. Exæquo, n.o 37, 2018, pp. 33-46. DOI: https://doi.org/10.22355/exaequo.2018.37.03. Acesso em: 18/03/2021.

FURLIN, Neiva. Políticas educacionais com perspectiva de gênero nos governos de Michelle Bachelet e Dilma Roussef. Revista Sociedade e Estado - Volume 36, Número 1, Janeiro / Abril 2021. Acesso em: 01/09/2021. Disponível em: https://periodicos.unb.br/index.php/sociedade/article/view/28233/29758.

GUIZO, Bianca Salazar. Gênero e sexualidade em políticas contemporâneas: entrelaces com a educação. Roteiro, Joaçaba, v. 41, n.2, p. 475-490, maio/ago.2016. Acesso em: 25/07/2021. Disponível em: https://portalperiodicos.unoesc.edu.br/roteiro/article/view/7546 KLUG, MArlise; LIMA, Rosimeire; LEBEDEFF, Tatiane. A leitura em sala de aula como mediadora de construção de igualdade de gênero. Interthesis. Vol. 13. №01. Jan/Abril 2013. Disponível em: http://dx.doi.org/10.5007/1807-1384.2016v13n1p95. Acesso em: 28/08/2021.

LAZZAROTTO, Gislei; CARVALHO, Julia. Afetar. In. FONSECA, Tania; NASCIMENTO, Maria Lívia; MARASCHIN, Cleci (Orgs.). Pesquisar na diferença: um abecedário.Porto Alegre: Sulina, 2012.

LEMOS; Flávia Cristina; ROCHA, Marisa Lopes. In. FONSECA, Tania; NASCIMENTO, Maria Lívia; MARASCHIN, Cleci (Orgs.). Pesquisar na diferença: um abecedário. Porto Alegre: Sulina, 2012. 
LOPES; Saskia. Interseccionalidade de raça e gênero nas escolas brasileiras e os projetos de lei silenciadores. Motricidades. v.2, n.2, p. 149-162, maio-ago. 2018. Disponínel em: http://dx.doi.org/10.29181/2594-6463.2018.v2.n2.p149-162. Acesso em: 31/08/2021.

LOURO, Guacira. Educação e docência: diversidade, gênero e sexualidade. Formação docente. Belo Horizonte, v.03, n.04, p. 62-70. Jan/jul.2011. Disponível em: https://revformacaodocente.com.br/index.php/rbpfp/article/view/31. Acesso em: 20/08/2021.

MEYER, Dagmar. Currículo de Gênero e sexualidade sobre tormentas e resistências criativas em territórios disputados. IN. PARAísO, Marlucy Alves; CALDEIRA, Maria Carolina. Pesquisas sobre currículos, gêneros e sexualidades. Belo Horizonte: Mazza edições, 2018.

NETO, Antônio Rodrigues; SANTOS, Isabelle Dias. A educação em gênero e a diversidade sexual na promoção da igualdade de gênero: a conquista da cidadania negra. Revista Artemis. Vol. XXVIII. №01. Julho-dez-2019. P. 209-226. Disponível em: https://periodicos.ufpb.br/index.php/artemis/article/view/43920. Acesso em: 28/08/2021.

PARAIISO, Marlucy Alves. Metodologia pesquisa pós-crítica em educação e currículo: trajetórias, pressupostos, procedimentos e estratégias analíticas. IN. MEYER, Dagmar; PARAíSO, Marlucy Alves. Metodologias de Pesquisa pós-críticas em educação. Belo Horizonte: Mazza edições, 2018.

RAMALHO, Carla; VIEIRA, José. Do projeto de lei 8.035/2010 à lei 13.005/2014: a inviabilização da temática gênero. Textura. v. 21 n. 48 p. 179-201 out./dez. 2019. Disponível em: https://doi.org/10.17648/textura-2358-0801-21-48-5254. Acesso em: $31 / 08 / 2021$.

RIBEIRO, Vanda; MARTINIC, Sergio; BONAMICO, Alicia. Implementação de políticas educacionais e equidade: regulação e mediação. Cad. Pesqui. São Paulo. V.50. no177. P. 698 - 717. Jul/set. 2020. Disponível em: https://doi.org/10.1590/198053146982. Acesso em: 28.08.2021.

ROSENO, Camila dos Passos; SILVA, Janaina Guimarães. POLÍTICAS PÚBLICAS EDUCACIONAIS EM GÊNERO E DIVERSIDADE SEXUAL: Atos de resistência diante do avanço do conservadorismo do movimento "Escola Sem Partido", Itinerarius Reflectionis. Volume, 13, n. 2, Ano 2017. Disponível em: https://www.revistas.ufg.br/rir/article/view/47804 Acesso em: 11/04/2021.

SILVA, Denise; COSTA, Zuleika; MULLER, Márcia. Gênero, sexualidade e políticas públicas de educação. Educação (Porto Alegre), v. 41, n. 01, p. 49 - 58, jan - abril - 2019. Acesso em: 30/08/2021. Disponível em: https://revistaseletronicas.pucrs.br/ojs/index.php/faced/article/view/29812.

VIEIRA, Viviane; GONZALEZ, Caroline. Seleção lexical e relações semânticas das coocorrências de gênero e sexualidade nos parâmetros curriculares nacionais. Alfa, São Paulo, v.63, n.1, p.153-180, 2019. Disponível em: http://doi.org/10.1590/1981-5794-1904-7 Acesso em: 31/08/2021.

VIEIRA, Rafael; LAGE, Allene. O gênero em disputa: ausências e presenças da demanda LGBT na escola. Inter-Ação, Goiânia, v. 42, n. 3, p. 590-607, set./dez. 2017. Disponível em: <http://dx.doi.org/10.5216/ia.v42i3.48981 >. Acesso em: 15/04/2021.

ZANELLA, Andréa. Olhar. In. FONSECA, Tania; NASCIMENTO, Maria Lívia; MARASCHIN, Cleci (Orgs.). Pesquisar na diferença: um abecedário. Porto Alegre: Sulina, 2012. 